\title{
Klaus Hildebrand, Geschichte des Dritten Reiches
}

München : Oldenbourg, 1979, rééd. 2012, 179 p., 19,80€

Johann Chapoutot

\section{OpenEdition}

\section{Journals}

Édition électronique

URL : http://journals.openedition.org/ifha/7702

DOI : 10.4000/ifha.7702

ISSN : 2198-8943

Éditeur

IFRA - Institut franco-allemand (sciences historiques et sociales)

Référence électronique

Johann Chapoutot, "Klaus Hildebrand, Geschichte des Dritten Reiches », Revue de I'IFHA [En ligne], Date de recension, mis en ligne le 13 décembre 2013, consulté le 22 septembre 2020. URL : http:// journals.openedition.org/ifha/7702 ; DOI : https://doi.org/10.4000/ifha.7702

Ce document a été généré automatiquement le 22 septembre 2020

CIFHA 


\section{Klaus Hildebrand, Geschichte des Dritten Reiches}

München : Oldenbourg, 1979, rééd. 2012, 179 p., 19,80€

Johann Chapoutot

Proposer une histoire du IIIème Reich en 178 pages était un défi : Klaus Hildebrand l'a relevé en 1979 avec un ouvrage que les éditions Oldenbourg rééditent en 2012 dans une version actualisée - mais sans préciser qu'il s'agit d'une réédition. L'historien, professeur émérite à Bonn, offre au lecteur intéressé et, surtout, à l'étudiant, une synthèse accessible, riche en citations tirées de sources et d'ouvrages scientifiques, précise dans l'exposé des faits et exhaustive, autant que faire se peut. La bibliographie, concise, tient en quelques pages et offre un premier panorama bienvenu de l'histoire de la période nazie : aux côtés de grands et vénérables classiques de l'historiographie, on trouve de nombreux ouvrages publiés dans les années 1990-2000 - quasi-exclusivement allemands et en langue allemande.

L'exposé est classique. Chronologique, il distingue quatre phases : à celle de la "prise de pouvoir » et de la "mise au pas », expressions nazies que l'auteur ne cite qu'entre guillemets (1933-1935), succède la "préparation à la guerre»(1936-1939), puis "l'Allemagne en guerre » (1939-1942) et, enfin, le passage de " la puissance mondiale à l'effondrement » (1943-1945). Chaque partie, par ailleurs, est subdivisée en deux mouvements qui, grosso modo, examinent les aspects intérieurs et les aspects extérieurs de l'histoire du Reich, distinction qui s'estompent de manière croissante à partir de 1939. Enfin, un résumé des propos et de l'évolution de la période est proposé à la fin de chaque séquence.

L'ensemble est d'une irréprochable solidité. L'auteur met à la disposition du public des éléments de connaissance et, plus prudemment, d'interprétation, que le lecteur ne pourrait se procurer sinon qu'au prix de lectures innombrables. On trouve donc dans ce livre le fruit d'une activité de lecture et de synthèse qui est celle d'une vie d'enseignement.

On est sans doute moins convaincu par la conclusion qui porte sur « le Troisième Reich dans l'histoire allemande et européenne ». Tout en soulignant à très juste titre que la 
séquence nazie n'est pas le produit exclusif et nécessaire de l'histoire allemande qui la précède, l'auteur ne relie pas assez cette période à l'histoire européenne et occidentale dont elle est partie intégrante. Bien au contraire, l'auteur estime que le IIIème Reich, par l'ampleur de ses crimes, «est exorbitante (...) à l'histoire allemande et européenne » (p. 168), si bien que l'on ne sait plus vraiment d'où il surgit et de quoi il participe. A côté de suggestions stimulantes portant sur les rapports entre raison et sentiment, l'auteur pose également des thèses d'interprétation massives, présentées sans discussion ni contextualisation: le nazisme serait ainsi le résultat d'un défaut de capitalisme (p.171), ce qui eût a minima appelé une brève démonstration, de même que, à plusieurs reprises au cours du texte, les conservateurs et les libéraux sont posés en alternative idéologique, éthique et pratique au national-socialisme, dont ils auraient finalement été vainqueurs.

Enfin, l'auteur reste fidèle à une historiographie de la "dictature» et du "totalitarisme" - notions que les spécialistes actuels du nazisme ont tendance à questionner en profondeur.

Il reste que cet ouvrage présente un compendium utile et accessible d'une histoire dont la présence dans les médias et l'enseignement scolaire laisserait accroire qu'elle est connue. La lecture de Klaus Hildebrandt démontrerait à beaucoup que ce n'est pas le cas.

INDEX

Index chronologique : Neuere und Neueste Geschichte

Thèmes : Politische Geschichte

\section{AUTEUR}

JOHANN CHAPOUTOT

Université de Grenoble 